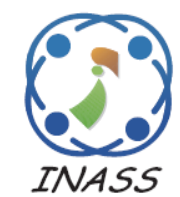

\title{
A Novel Configuration of a Miniature Printed Antenna Array Based on Defected Ground Structure
}

\author{
Ahmed Ghaloua ${ }^{1 *}$ \\ Jamal Zbitou ${ }^{1}$ \\ Larbi El Abdellaoui ${ }^{1}$ \\ Mohamed Latrach ${ }^{2}$ \\ Abdelali Tajmouati $^{1} \quad$ Ahmed Errkik $^{1}$ \\ ${ }^{1}$ Laboratory of Mechanics, Energetics, Electronics and Telecommunications, FST of Settat, \\ University of Hassan 1st, Morocco \\ ${ }^{2}$ Microwave Group, Ecole Supérieure d'Electronique de l'Ouest, Angers, France \\ * Corresponding author's Email: ahmed.ghaloua@ gmail.com
}

\begin{abstract}
In this paper, a highly miniaturized microstrip antenna array is proposed for the small wireless device. The antenna array is designed to cover the Industrial Scientific Medical band (ISM) at $2.45 \mathrm{GHz}$. The antenna array is miniaturized using a new geometry of defected ground structure (DGS) etched in the ground plane of each radiating element of the antenna array. The array size is $140.74 \mathrm{~mm}$ by $57.15 \mathrm{~mm}$, which means $78.63 \%$ miniaturization ratio is achieved at $2.45 \mathrm{GHz}$ as compared with a conventional microstrip antenna array with an ordinary ground plane of $367.26 \times 102.46 \mathrm{~mm}^{2}$ resonating at the same frequency $(2.45 \mathrm{GHz})$. The structure is implemented on an FR-4 substrate of a relative permittivity equal to $4.4,1.6 \mathrm{~mm}$ of thickness and 0.025 of loss tangent. This compact antenna array is designed and optimized by using the electromagnetic solver based on finite integration technique, and the results agree with those obtained by the high-frequency electromagnetic field simulation solution (HFSS). The simulated $10-\mathrm{dB}$ return-loss bandwidth of the printed array is about $157.5 \mathrm{MHz}$, whereas the value of gain is about $7.026 \mathrm{~dB}$, which is relatively satisfied. Finally, the final circuit of miniaturized antenna array is fabricated and measured.
\end{abstract}

Keywords: Defected ground structure (DGS), $\pi$-Type equivalent circuit model, Miniaturization, Printed antenna array, ISM band.

\section{Introduction}

Unlike communication with wire, which needs a more expensive installation and a lot of time to implement its architecture, wireless technology is used in many types of communication because it is cheaper and more flexible than running cables. Without forget the different roles of the other equipment (power amplifier, power limiter, coupler, modulator, oscillator...) that exists either in the transmitting or in the receiving chain block of a wireless communication system, the main equipment in the wireless communications system is the antenna. An antenna is a transducer, which converts one form of energy into another [1]. It is designed to receive or transmit electromagnetic waves from one source to one or any destinations.
During the design of the compact telecommunications system, we are always looking to miniaturize the different equipment's coming into this mission, for example, the microstrip patch antenna. The patch antenna or the printed antenna finding increasing application in the commercial sector of the industry, because of their low profile, low weight, and lower manufacturing cost [2]. A lot of research has been undertaken to overcome the disadvantages associated with the microstrip patch antenna. Typically, the array arrangements of microstrip antennas are used to widen the bandwidth or to improve the efficiency, directivity, and gain for the radiating system [3]. Sometimes becomes impossible the use of an antenna array to improve the transmission performances of the wireless communication equipment, because of its geometric 
dimensions, which are wider compared to its reserved location in the system box.

For several years, the work of researchers and designers is mainly focused on tools development allowing the miniaturization of the antennas and integrated circuits in order to obtain miniaturized communicating objects. Many applications related to either the air vehicle or the navigation system or /and the radar require a significant effort to obtain a small-size antenna array with the acceptable performances in terms of bandwidth, gain, and efficiency- note that, in the design process of a miniaturized array, the gain of the antenna array diminishes-. In fact, different strategies are already proposed to reduce the size of the antenna array, some of which are essentially based on the miniaturization of the antenna. -The most famous method used to miniaturize the microstrip patch antenna is the Magneto-dielectric substrate, indeed, is a substrate with high-electric permittivity that has been proposed in [4 - 6]. A number of parallel splitring resonators (SRRs) has realized this last method. Another method based on two-dimensional (2D) high-constitutive parameter (TDHCP) substrate is used for miniaturizing of a circularly-polarised microstrip patch antenna [7]. Recently, defected ground structure (DGS) [8 - 10], defected microstrip structure (DMS) [11] and electromagnetic band gap structure (EBGs) [12 - 15] have received a lot of attention because of their ease, also the flexibility to introduce into the designs of the structures often require that the circuits be as small as possible, for instance, radars, satellites and also mobiles communications systems-. Subsequently, the design of a compact antenna array becomes an easier task to achieve. On the other side, many researchers have demonstrated that use the electromagnetic bandgap (EBG) structure [16 - 18] or the neutralization lines technique [19 - 21] are able to reduce the mutual coupling between the closely spaced radiating elements and actually to have a small-size antenna array. As the techniques develop, some interdigital resonators with simpler structures are studied to decrease the mutual coupling between the adjacent patches and simultaneously to realize an ultracompact microstrip antenna array [22]. These techniques are, however, more complex and cannot always be implemented, due to requirements on simplicity and versatility. The miniaturization of the radiating element in a system requires a compromise to be found and made by the researcher because this operation has fundamental limitations. Different criteria exist taking into account the bandwidth, gain, and adaptation.
In this paper, we have explored the DGS method to design a $1 \times 4$ compact microstrip antenna array. As compared with the conventional printed array resonating at $2.45 \mathrm{GHz}, 78.63 \%$ miniaturization ratio is obtained by four unique shapes of defected ground structure (DGS) units etched in the ground plane of each radiating element of the antenna array. The novelty of the design comes from getting the highest miniaturization ratio with relatively acceptable radiation characteristics. This paper starts with the primary design of an elementary printed antenna used to design the planar array arrangements with four elements resonating at $5.8 \mathrm{GHz}$. In Section 3, a detailed description of the selected configuration of the DGS structure and its electrical model are described. Subsequently, Section 4 will deal with the different effects and modification caused by the insertion of the proposed shape of the DGS on its electrical and radiating characteristics. A prototype antenna array has been constructed, simulation and measurement results have been compared and discussed in Section 5 and Section 6 will present the conclusion of this paper. The concept that we have proposed in this work leads to a compact printed structure that can be implemented in several and different microwave communication devices.

\section{Printed antenna array}

The use of an antenna array plays a significant role for point-to-point communications, through the use of him, the efficiency, directivity and gain the radiating system is much improved. However, antenna array has certain disadvantages related to the dimensions of the structure, especially if the printed array have to be placed in a small location in the system housing. As a first step towards miniaturizing the antenna array, a single compact antenna resonates at $5.8 \mathrm{GHz}$ has been designed. Its width and length are calculated from the general equations discussed in the literature [23]. After that, we have modified its conventional form, which many slots in the y-shape are introduced in top layer on both ends in the microstrip patch antenna. After several optimizations using the 3D electromagnetic (EM) simulation software, we have finally a new concept of the printed antenna presented in Fig. 1. The novel proposed antenna is a planar microstrip antenna, is printed on a low-cost FR-4 substrate with a thickness of $1.6 \mathrm{~mm}$, relative permittivity of 4.4 , a loss tangent of 0.025 , with a total area of $35.74 \times 28.15 \mathrm{~mm}^{2}$. The optimized parameters of the printed antenna are $\mathrm{Lp}=10.33 \mathrm{~mm}, \mathrm{Lf}=7 \mathrm{~mm}$, Ly $1=1 \mathrm{~mm}, \mathrm{Ly} 2=2 \mathrm{~mm}, \mathrm{Ly} 3=5.8 \mathrm{~mm}, w p=11.15 \mathrm{~mm}$, 
and $\mathrm{wf}=0.5 \mathrm{~mm}$. With this modification, we have a reduction about $33 \%$ physical volume compared to the conventional structure, despite the fact that we have a small degradation at the gain level of $0.795 \mathrm{~dB}$ and around $58.8 \mathrm{MHz}$ of the bandwidth. From the Fig. 2, it is clearly shown that the working frequency of the antenna is $5.8 \mathrm{GHz}$, with a good return loss of $-24.97 \mathrm{~dB}$ as well as the frequency bandwidth $(\mathrm{S} 11 \leq-10 \mathrm{~dB})$ is $174 \mathrm{MHz}(5.7136 \mathrm{GHz}-$ $5.8876 \mathrm{GHz})$.

On the basis of the patch antenna mentioned above, we have developed the antenna array structure. The linear directional antenna array that was designed in this letter is consist of four $4 \times 1$ radiating elements etched on the same epoxy substrate, backed by a $140.74 \mathrm{mmx} 57.15 \mathrm{~mm}$ ground plane, with symmetrical corporate feeding networks and arrangements. Because is versatile and allow more control over the feed of each element along with ensuring maximum power transfer to each radiating element, the corporate feed network is used to construct this antenna array. The antenna array elements have separated by an edge-to-edge distance of $22.47 \mathrm{~mm} \mathrm{(d2}=0.43 \lambda_{5.8 \mathrm{GHz}}$, where $\lambda_{5.8 \mathrm{GHz}}$ is the free space wavelength at $5.8 \mathrm{GHz}$ ) and centerto-center separation of $33.62 \mathrm{~mm}\left(\mathrm{~d} 1=0.65 \lambda_{5.8 \mathrm{GHz}}\right)$. The antenna array full dimensions and the 3D-view of the design are shown in Fig. 3. The optimized physical dimensions are $\mathrm{a} 1=2.0 \mathrm{~mm}, \mathrm{a} 2=6.5 \mathrm{~mm}$, $\mathrm{a} 3=13.62 \mathrm{~mm}, \mathrm{a} 4=10.8 \mathrm{~mm}, \mathrm{a} 5=6.0 \mathrm{~mm}, \mathrm{a} 6=11.0 \mathrm{~mm}$, $\mathrm{a} 7=30.24 \mathrm{~mm}, \mathrm{a} 8=7.25 \mathrm{~mm}, \mathrm{a} 9=16.0 \mathrm{~mm}$, afed $=3 \mathrm{~mm}$, $\mathrm{b} 1=2.3 \mathrm{~mm}, \quad \mathrm{~b} 2=3.0 \mathrm{~mm}, \quad \mathrm{~b} 3=1.7 \mathrm{~mm}, \quad \mathrm{~b} 4=0.4 \mathrm{~mm}$, $\mathrm{b} 5=3.0 \mathrm{~mm}$, and Lfed $=11.25 \mathrm{~mm}$. The simulated return loss results of the antenna array is matched $(|\mathrm{S} 11|<-10 \mathrm{~dB})$ from $5712.9 \mathrm{MHz}$ to $5881.4 \mathrm{MHz}$. Besides, we note favorably that the gain is improved by $4.215 \mathrm{~dB}$. It can fulfill the requirements of indoor wireless applications very well.

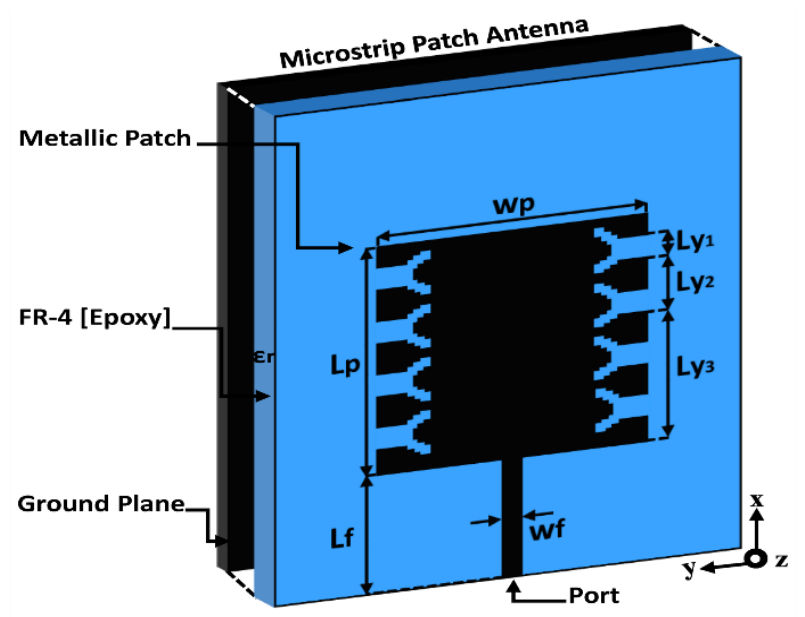

Figure. 1 Schematic diagram of the printed patch antenna

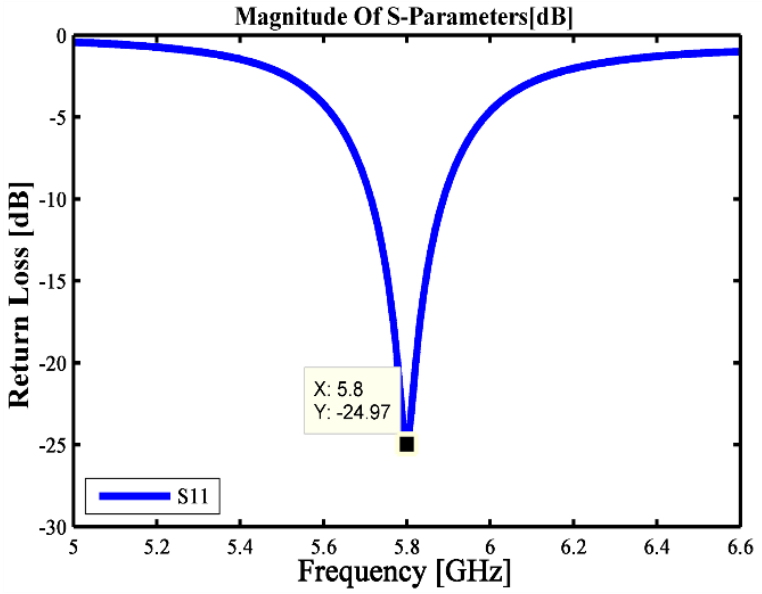

Figure. 2 Simulated return $|\mathrm{S} 11|$ loss of the printed antenna resonating at $5.8 \mathrm{GHz}$

\section{Configuration of defected ground structure}

To improve the performance of several microwave printed circuits or to adjust and refine the frequency response of the microstrip components, the ground plane is purposely modified by a slot or an aperture. The modifications of the ground plane are usually called "defects," and these defects in the ground plane give this name to this class of components. The defected ground structure can be realized by etching of a slots or a simple shape -complex shape for the better performance- in the ground plane, located directly under the microstrip line or beside the coplanar waveguide. According to the shape and dimensions of the defect, the shielded current distribution in the ground plane is disturbed, resulting from a controlled excitation and propagation of the electromagnetic waves through the substrate layer [24].

The dimensions of the aperture or slot are not randomly chosen, but instead are carefully selected in order to achieve the desired electromagnetic effect. DGS can be classified into two categories depending on their configurations: the first group comprises structures based on a single defect used to modify the frequency response of a printed circuit, whereas the second group encompasses structures based on a small number of defects, in a periodic or non-periodic arrangement, employ to enhancing the characteristics of single defects.

A $\pi$-type equivalent circuit model of a dumbbell DGS is shown in Fig. 4; is developed in [25], which is much suitable to the exigent precision of circuit design. The proposed equivalent circuit includes the series element is a classical parallel RLC resonator, and the shunt elements are parallel RC circuits. The parallel capacitance that is due to the relatively large 


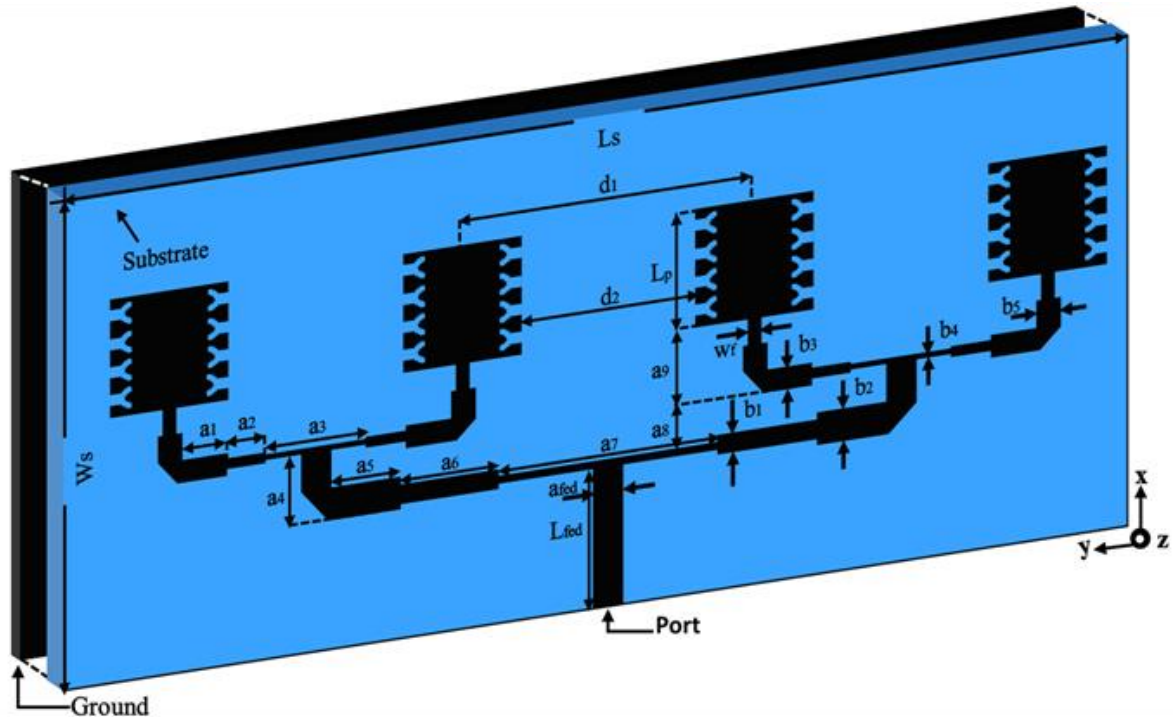

Figure. 3 Geometry of the proposed antenna array $4 \times 1$

fringing field at the step discontinuity plane on metallic ground surface. In order to derive the equivalent circuit parameters, the S-parameters of unit DGS cell at the reference plane should be calculated by EM-simulation. The value of the lumped elements of unit DGS cell can be derived from the full-wave analysis of the structure. Once the S-parameters are calculated, the ABCD parameters for the unit cell will be obtained using the expression as follows:

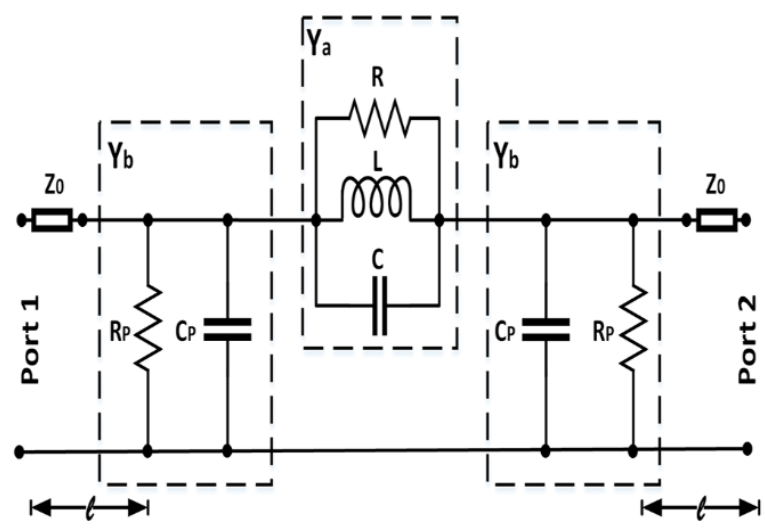

Figure. $4 \pi$-Type equivalent circuit model of DGS [25]

$$
\begin{aligned}
& \mathrm{A}=\frac{\left(1+\mathrm{S}_{11}\right)\left(1-\mathrm{S}_{22}\right)+\mathrm{S}_{12} \mathrm{~S}_{21}}{2 \mathrm{~S}_{21}}=1+\frac{\mathrm{Y}_{b}}{\mathrm{Y}_{a}} \\
& \mathrm{~B}=\frac{\left(1+\mathrm{S}_{11}\right)\left(1+\mathrm{S}_{22}\right)-\mathrm{S}_{12} \mathrm{~S}_{21}}{2 \mathrm{~S}_{21}}=\frac{1}{\mathrm{Y}_{a}} \\
& \mathrm{C}=\frac{1}{\mathrm{Z}_{0}} \frac{\left(1-\mathrm{S}_{11}\right)\left(1-\mathrm{S}_{22}\right)-\mathrm{S}_{12} \mathrm{~S}_{21}}{2 \mathrm{~S}_{21}}=2 \mathrm{Y}_{b}+\frac{\mathrm{Y}_{b}^{2}}{\mathrm{Y}_{a}} \\
& \mathrm{D}=\frac{\left(1-\mathrm{S}_{11}\right)\left(1+\mathrm{S}_{22}\right)+\mathrm{S}_{12} \mathrm{~S}_{21}}{2 \mathrm{~S}_{21}}=1+\frac{\mathrm{Y}_{b}}{\mathrm{Y}_{a}}
\end{aligned}
$$

The ABCD-parameters are related to the admittances of the $\pi$-type equivalent circuit model:

$$
\begin{gathered}
\mathrm{Y}_{a}=\frac{1}{B}=\frac{1}{R}+j\left(\omega C-\frac{1}{\omega L}\right) \\
\mathrm{Y}_{b}=\frac{A-1}{B}=\frac{-1 \pm \sqrt{1+B C}}{B}=\frac{D-1}{B}=\frac{1}{R_{p}}+j \omega C_{p}
\end{gathered}
$$

More specifically, the value of the lumped elements are given by:

$$
\begin{aligned}
& R=\frac{1}{\operatorname{Re}\left\{Y_{a}\right\}}, C=\frac{\operatorname{Im}\left\{Y_{a}\right\}}{\omega_{0}\left(\frac{\omega_{1}}{\omega_{0}}-\frac{\omega_{0}}{\omega_{1}}\right)} \\
& L=\frac{1}{\omega_{0}^{2} C}, R_{p}=\frac{1}{\operatorname{Re}\left\{Y_{b}\right\}}, C_{p}=\frac{\operatorname{Im}\left\{Y_{b}\right\}}{\omega_{1}}
\end{aligned}
$$

Instead of the conventional DGSs, like the classic dumbbell and arrowhead-slot or U-shaped DGS in the ground plane, the concept of the geometry of the defect explored in the present design is simple and looks like a bone as shown in Fig. 5. This DGS shape is composed of two hearts shape defected areas connected by a narrow slot in backside metallic ground plane, where WDGS3, WDGS2, LDGS1 and LDGS2 are horizontal and vertical length of the aperture and etched gap distance. The strategic location and dimensions of the defect are chosen in such a way that these structures do not interfere with each other when we manufacture the antenna array. 


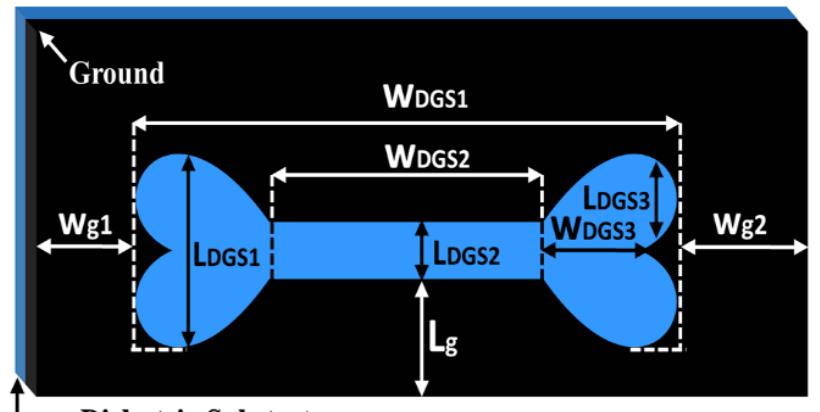

Dielectric Substrate

Figure. 5 Scheme of the compact defected ground structure. WDGS1 $=26.94 \mathrm{~mm}$, WDGS2 $=22 \mathrm{~mm}$, WDGS3 $=1.6 \mathrm{~mm}, \mathrm{LDGS} 1=4.94 \mathrm{~mm}, \mathrm{LDGS} 2=2.17 \mathrm{~mm}$, LDGS3 $=1.85 \mathrm{~mm}, \mathrm{Wg} 1=4.26 \mathrm{~mm}, \mathrm{Wg} 2=6.97 \mathrm{~mm}$ and $\mathrm{Lg}=12.09 \mathrm{~mm}$

\section{Printed antenna array with defected ground structure}

The design of a low-profile antenna array at this frequency $2.45 \mathrm{GHz}$ is quite challenging, even more, while considering the proposed approach is much more compact compared to several ground structure described in previous research. The effect of introducing the defected ground structure (DGS) into the ground plane of the microstrip antenna array on the resonant frequency as well as the gain is illustrated in Fig. 7 and Fig. 8, respectively. It is clear that insertion of the geometry DGS in the ground plane of the antenna, cheek a very sensitive role, moreover it has a very strong impact to expect the good performances.
It is interesting to study the change of the performances the antenna array at the various parameters. Our new structure of DGS present several design parameters (WDGS1, WDGS2, WDGS3, LDGS1, LDGS2, LDGS3, Wg1, Wg2 and $\mathrm{Lg}$ ). We vary one dimension (parameter: LDGS2) of DGS keeping other parameters fixed. The variabilities of the return loss coefficient that have occurred through the change of DGS dimension 'LDGS2' and its position relative to radiating elements ' $\mathrm{H}$ ' of the antenna array are depicted in the following Figures. It can be observed that the reduction of the width of the slot that links the two hearts shape defected areas, shifts the resonant frequency of the printed antenna array from $2.52 \mathrm{GHz}$ to $2.156 \mathrm{GHz}$. The variation of the location of the DGS located under the radiating patch, indeed, the displace of the DGS towards the direction of the length of the antenna- causes of shifting the resonant frequency from $5.8 \mathrm{GHz}$ to a lower frequency. Consequently, the bandwidth becomes a bit narrow. In addition, as can be seen in Fig. 8(b), we have also a degradation of the gain cannot be ignored.

After optimizing many parameters of the proposed defected ground structure etched in the ground plane under each radiating element of the antenna array they are symmetrically located on the y-axis-, by using the 3D electromagnetic (EM) simulation software, we have validated the final antenna array geometry. In order to check the results obtained by using the electromagnetic solver based on the finite

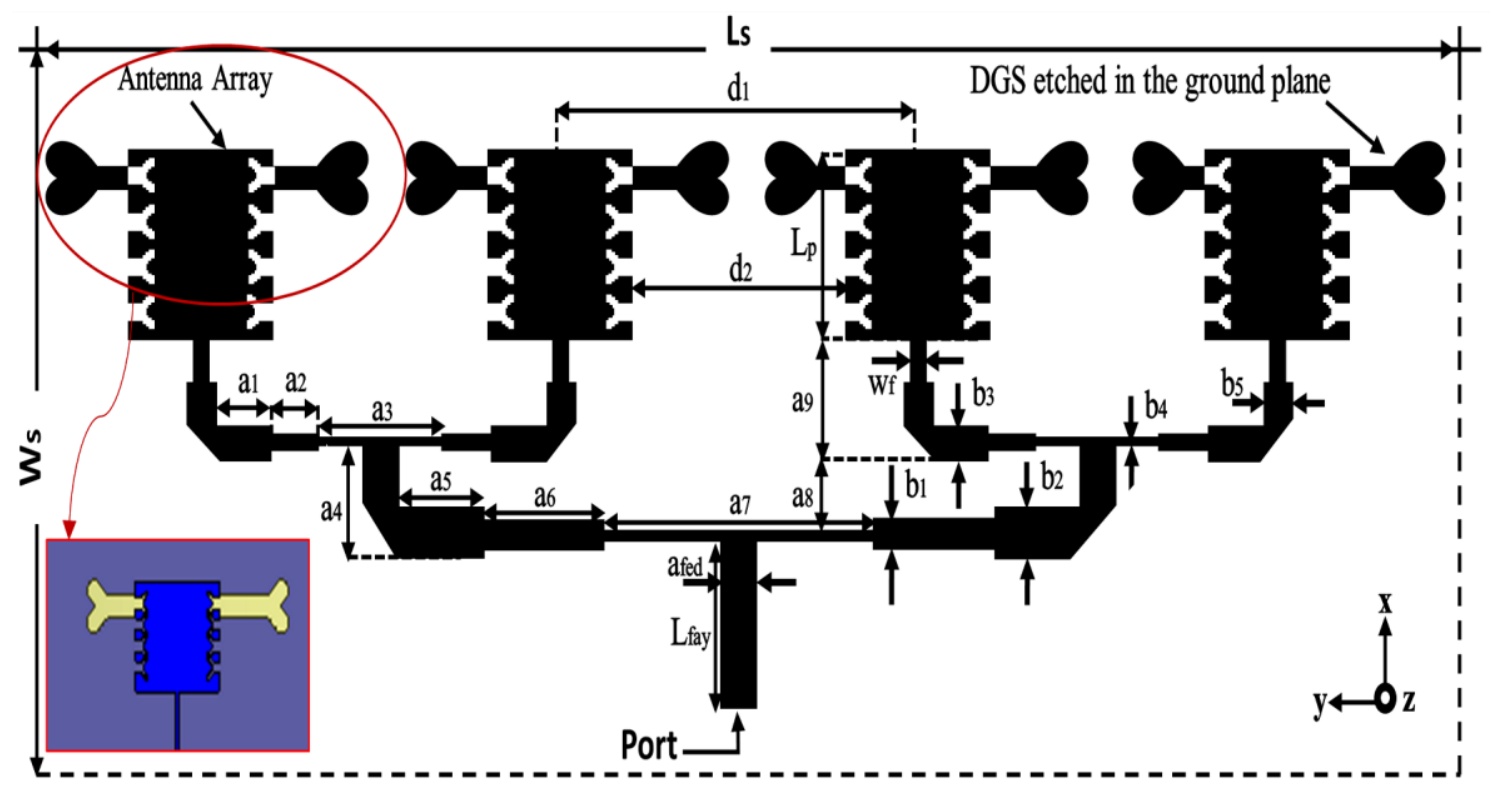

Figure. 6 Configuration of the proposed $4 \times 1$ antenna array with defected ground structure (DGS) 
integration technique (FIT), it was absolutely necessary to use another electromagnetic solver HFSS software where the numerical analysis is based on the Finite-Element Method (FEM). Fig. 9 shows the simulated input reflection coefficient against the frequency of the final circuit. According to this figure, the results of reflection coefficient computed by the 3D electromagnetic (EM) simulation software are similar to the results obtained by HFSS. The minor difference observed is due to the different calculation methods used by both simulators. From the Fig. 3, the antenna array initially resonates at $5.8 \mathrm{GHz}$ without the DGS. Using the optimal placement and suitable size of the DGS, the resonant frequency was decreased to $2.45 \mathrm{GHz}$ with the return loss better than $-26 \mathrm{~dB}$, which represents a $57.76 \%$ decrease. In compliance with some reports in the literature, the size of an antenna array can only be reduced at the expense of its bandwidth and gain. Always in this context, the bandwidth of the antenna array without the DGS is $168.5 \mathrm{MHz}$, while the frequency bandwidth of the antenna array with DGS $(\mathrm{S} 11 \leq-10 \mathrm{~dB})$ is $157.5 \mathrm{MHz}$ $(2.3721 \mathrm{GHz}-2.5296 \mathrm{GHz})$, which covers the operating frequency of the Industrial Scientific Medical (ISM) band. We deduced that there is a difference of $11 \mathrm{MHz}$ of the impedance bandwidth between the antenna array without and with DGS.

As Fig. 10 indicates, that employing the defected ground plane beneath the printed antenna array not only diminish the impedance bandwidth, but also reduce the gain value. Moreover, as can be clearly seen from the same graph, the simulated gain at $5.8 \mathrm{GHz}$ is $8.226 \mathrm{~dB}$, while the simulated gain of the antenna array with DGS at $2.45 \mathrm{GHz}$ is $7.026 \mathrm{~dB}$. Fig. 11 , shows the current distribution of the antenna array before and after the implementation of the DGS respectively at $5.8 \mathrm{GHz}$ and $2.45 \mathrm{GHz}$. It clearly observed that a maximum current is shown around the feed network and the extremities of radiating elements at $5.8 \mathrm{GHz}$. While at $2.45 \mathrm{GHz}$, the density of current is also concentrated around DGS slots. The simulated radiations patterns of the proposed antenna array with and without defected ground structure at $5.8 \mathrm{GHz}$ and $2.45 \mathrm{GHz}$ respectively are shown in Fig. 14. From the radiations plot, it is evident that the conventional antenna array without DGS radiate in one side and has a half-power beam width less than $25 \mathrm{deg}$ in the principal plane. Whereas the proposed antenna array radiate on both sides of the ground plane due to the aperture of defected ground structure. The $3-\mathrm{dB}$ beam-width of the proposed microstrip antenna array is about 41.8 deg from theta $=-157.5 \mathrm{deg}$ to theta $=160.7 \mathrm{deg}$.

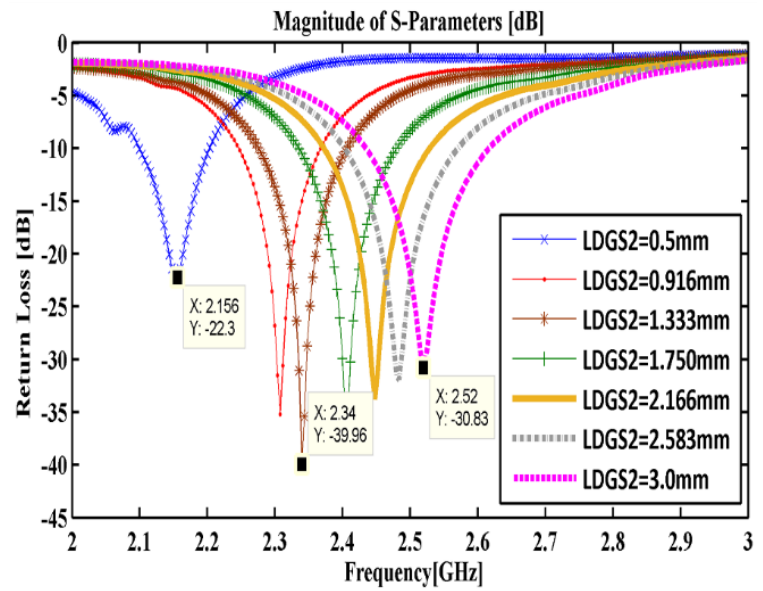

Figure. 7 Return loss versus frequency of the proposed antenna array with DGS for different values of LDGS2

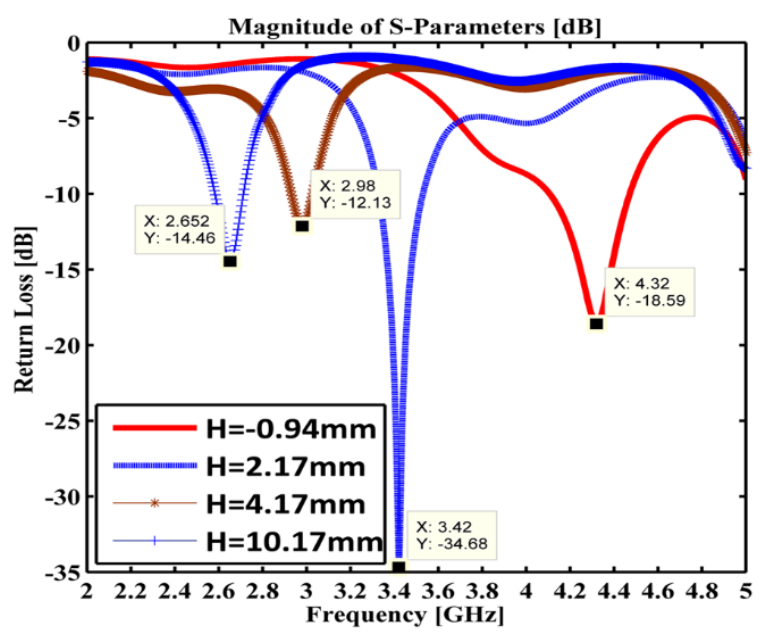

(a)

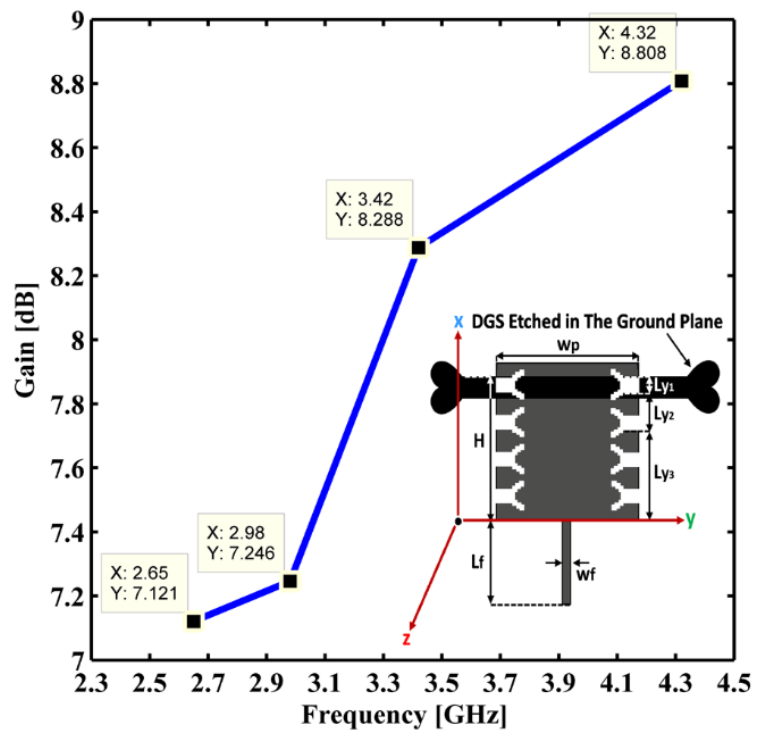

(b)

Figure. 8 Investigation of return loss and gain of the proposed antenna array with DGS for different values of $\mathrm{H}$, based on simulated results 


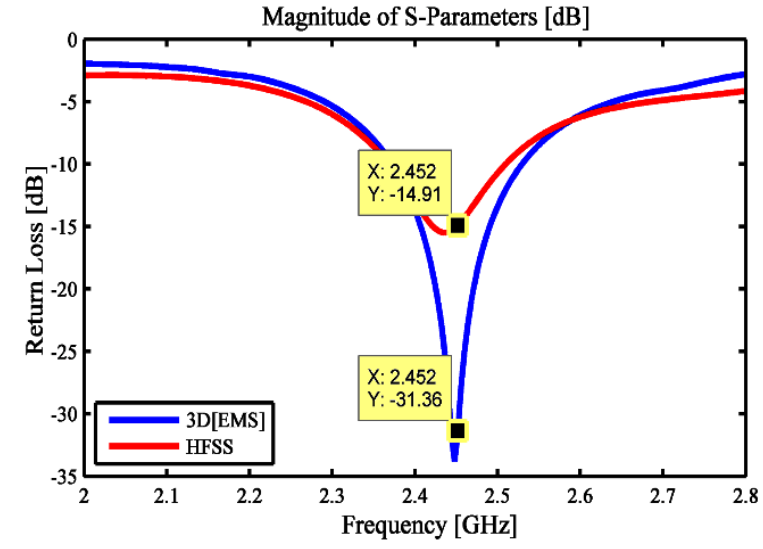

Figure. 9 Comparison of return loss between 3D electromagnetic (EM) simulation software and HFSS for the final circuit

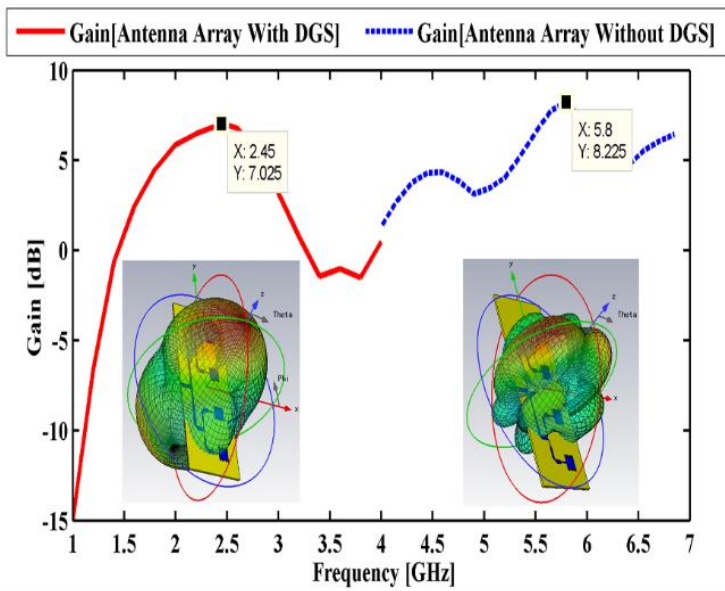

Figure. 10 The gain vs frequency comparison for the patch array with and without DGS

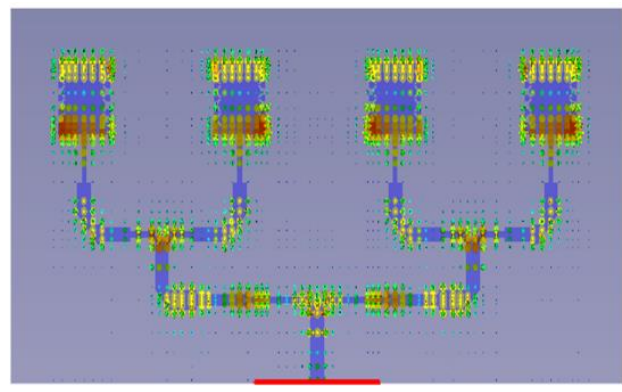

(a)

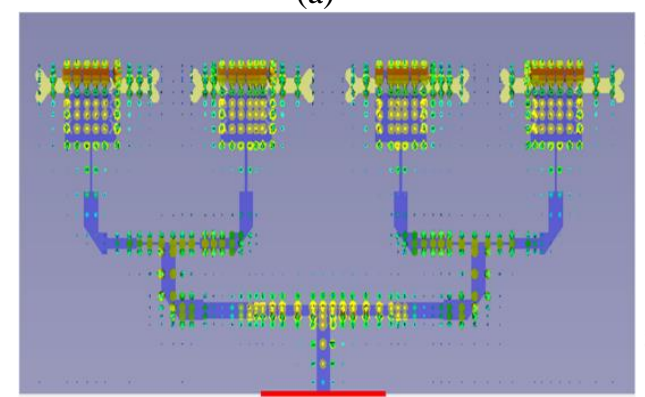

(b)

Figure. 11 The Surface current distributions at: (a) $5.8 \mathrm{GHz}$ without DGS and (b) $2.45 \mathrm{GHz}$ with DGS

\section{Fabrication, measurement, and comparison}

DGS introduced a defected shape in backside metallic ground plane of the antenna array. This technique does not impose any extra volume and cost in fabrication as well as easy to achieve. These features preserve the advantages of microstrip antenna array, which are low profile and low weight. To further verify properties of the proposed approach, a designed prototype of the highly miniaturized antenna array shown in Fig. 6 is fabricated on the FR-4 substrate with a thickness of $1.58 \mathrm{~mm}$, a relative electric constant of 4.4 , a loss tangent of 0.025 and a conductor thickness of $35 \mathrm{um}$ using LPKF machine. The circuit size is relatively small, with an area nearly equal to $\left(140.74 \times 57.15 \mathrm{~mm}^{2}\right)$. Its fabricated picture is shown in Fig. 12. The network analyzer N5247A, US50470114 from the Agilent Technologies is used to characterize the measured S-parameter of the manufactured antenna array. The simulated and measured reflection coefficients are illustrated in Fig. 13 , where a wide $10 \mathrm{~dB}$ impedance bandwidth of $4.32 \%$, i.e., from $2380 \mathrm{MHz}$ to $2485 \mathrm{MHz}$, which is wide enough considering the antenna array size. The measured reflection coefficient is slightly different to the simulated results in term of matching input impedance at $2.45 \mathrm{GHz}$; their differences are probably due to the dimensional fabrication tolerances and/or dissimilarity in permittivity of substrate material between simulated and actual value. The far-field radiation pattern of this sample is measured in an anechoic chamber. As can be seen in Fig. 14, the measurement result shows that the loading of DGS influences the radiation characteristic of the patch array, such as the antenna array became bidirectional radiation pattern. The comparison of both plots obtained from the two electromagnetic solvers and the VNA are listed in Table 1. The discrepancies between the two simulation results are due to different analytical techniques and different mesh sizes of the two simulators. Finally, the Table 2 shows a comparison between the proposed circuit and other miniaturized antenna array that appeared in previously published papers in terms of dimensions, miniaturization ratio, gain and number of unit elements. We can clearly observe that the proposed printed antenna array has a high miniaturization ratio with an acceptable gain. 


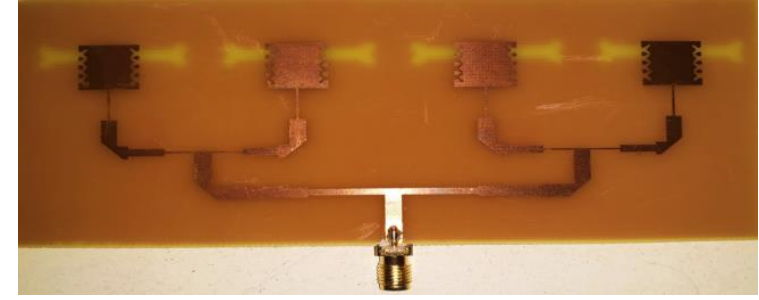

(a)

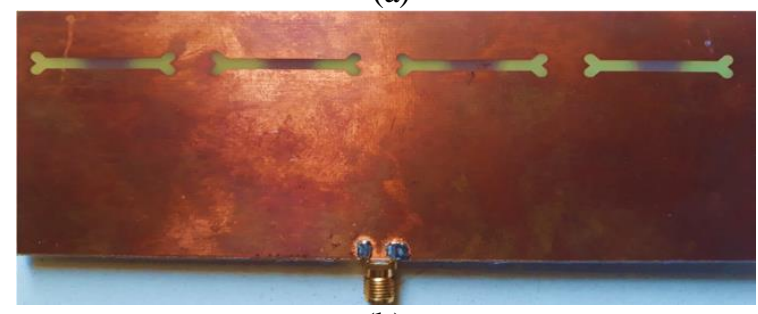

(b)

Figure. 12 A photograph of the fabricated antenna array with DGS: (a) Front view, and (b) Back view

Table 1. Comparison between simulation and measurement results of the proposed circuit

\begin{tabular}{|c|c|c|c|}
\hline Parameters & $\begin{array}{c}\text { Simulated } \\
\text { Results by } \\
\text { 3D(EMS) }\end{array}$ & $\begin{array}{c}\text { Simulated } \\
\text { Results by } \\
\text { HFSS }\end{array}$ & $\begin{array}{c}\text { Measured } \\
\text { Results }\end{array}$ \\
\hline Frequency & $2.45 \mathrm{GHz}$ & $2.45 \mathrm{GHz}$ & $2.45 \mathrm{GHz}$ \\
\hline Return Loss & $-32.59 \mathrm{~dB}$ & $-15.03 \mathrm{~dB}$ & $-11.59 \mathrm{~dB}$ \\
\hline Bandwidth & $157.5 \mathrm{MHz}$ & $141.2 \mathrm{MHz}$ & $105.0 \mathrm{MHz}$ \\
\hline Gain & $7.026 \mathrm{~dB}$ & $6.09 \mathrm{~dB}$ & - \\
\hline
\end{tabular}

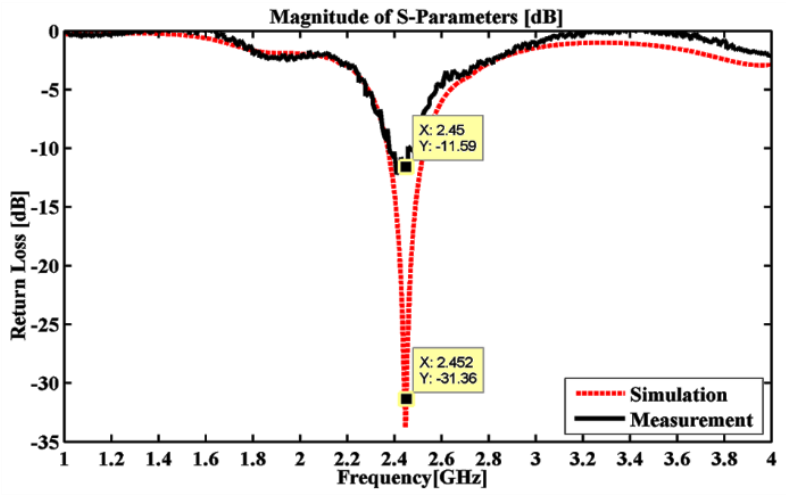

Figure. 13 Measured and simulated reflection coefficient of the proposed circuit

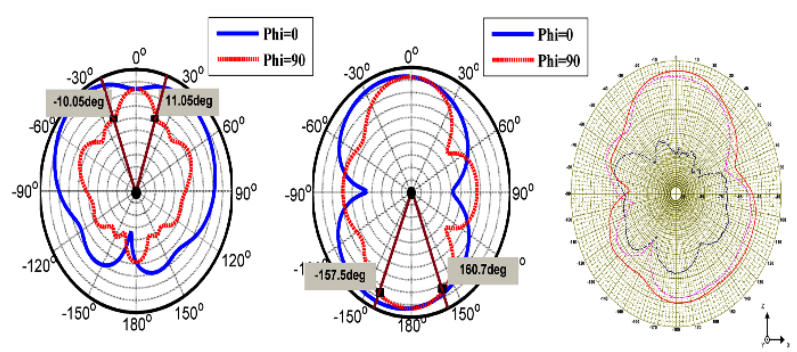

(a)

(b)

(c)

Figure. 14 Radiation patterns of the proposed antenna array: Simulated radiation patterns: (a) without DGS, (b) with DGS, and (c) measured radiation patterns of the manufactured antenna array at $2.45 \mathrm{GHz}$ in E-plane for 0deg, 45deg and 90deg

Table 2. The state of the art comparison between the proposed miniature antenna array using the DGS and other solutions published in literature

\begin{tabular}{|c|c|c|c|c|c|c|}
\hline Ref., year & Technique & Frequency & Dimension & Gain & MNR* & NUE* \\
\hline [26], 2013 & $\begin{array}{l}\text { Left-Handed Unit } \\
\text { Cell And Defected } \\
\text { Ground Structure } \\
\text { (DGS) }\end{array}$ & $5.8 \mathrm{GHz}$ & $26 \times 23.6 \mathrm{~mm}^{2}$ & $9.99 \mathrm{~dB}$ & $50 \%$ & 2 \\
\hline [27], 2016 & $\begin{array}{l}\text { Defected Ground } \\
\text { Structure (DGS) }\end{array}$ & $\begin{array}{c}\text { LTE } \\
700 / 850 / 900 \mathrm{MHz}\end{array}$ & $\pi \times 802 \times 50 \mathrm{~mm}^{3}$ & - & - & 4 \\
\hline [28], 2017 & $\begin{array}{c}\text { Slotted Annular } \\
\text { Ring Monopole } \\
\text { Antenna }\end{array}$ & 3 to $15 \mathrm{GHz}$ & $38 \times 90 \times 0.762 \mathrm{~mm}^{3}$ & 0.5 to $5 \mathrm{dBi}$ & - & 8 \\
\hline [29], 2018 & $\begin{array}{c}\text { BND antenna } \\
\text { elements and AMC } \\
\text { reflectors }\end{array}$ & $\begin{array}{c}1.8 \mathrm{GHz} \text { and } 2.05 \\
\mathrm{GHz}\end{array}$ & $\begin{array}{l}560 \times 165 \mathrm{~mm}^{2} \\
\text { and } \\
558 \times 164 \mathrm{~mm}^{2}\end{array}$ & $\begin{array}{c}\text { DCS band: } \\
\text { [12.1-12.6 } \\
\text { dBi] } \\
\text { WCDMA } \\
\text { band : [12.4- } \\
13.1 \mathrm{dBi}]\end{array}$ & $\begin{array}{c}46.3 \% \\
\text { and } \\
19.9 \%\end{array}$ & 8 \\
\hline This Work & $\begin{array}{l}\text { Defected Ground } \\
\text { Structure (DGS) }\end{array}$ & $2.45 \mathrm{GHz}$ & $\begin{array}{c}140.74 \times 57.15 \times 1.67 \\
\mathrm{~mm}^{3}\end{array}$ & $7.026 \mathrm{~dB}$ & $\begin{array}{c}78.63 \\
\%\end{array}$ & 4 \\
\hline
\end{tabular}

\section{Notice:}

*NUE: Number of unit elements

$*$ MNR: Miniaturization Ratio (For this structure) $=\left(\frac{(367.26 * 102.46)-(140.74 * 57.15)}{(367.26 * 102.46)}\right) * 100$ 


\section{Conclusion}

This paper presents a novel approach to achieve a very compact printed antenna array. Four unique symmetric shapes of defected ground structure (DGS) placed in the ground plane, under each radiating element of the antenna array. In this manner, we have been able to reduce the antenna array size up to $78.63 \%$ as compared with the conventional printed antenna array resonating at the same frequency $(2.45 \mathrm{GHz})$. A designed prototype is being fabricated by using the low-cost printedcircuit-board (PCB) technology, and the measurement results are discussed. Compared to others miniaturization techniques already exist, the proposed approach combined with the patch array exhibited an acceptable bandwidth, Gain, and radiation characteristics for ISM applications, as well as the main advantage of this technique, is that the performances of the patch array can be easily optimized to meet specific requirements. In future work, the use of defected Ground Structure (DGS) in combination with the Electromagnetic Band-Gap (EBG) Structure for other structures of antennas arrays that have numerous number of unit elements should be investigated in order to get simultaneously a low mutual coupling and a highly miniaturized design.

\section{References}

[1] A. B. Constantine, Antenna theory: analysis and design, John Wiley \& Sons, New Jersey, 2005.

[2] J. R. James, P. S. Hall, and C. Wood, Microstrip antenna: theory and design, No. 12. Iet, 1986.

[3] D. Liu, U. Pfeiffer, J. Grzyb, and B. Gaucher, Advanced millimeter-wave technologies: antennas, packaging and circuits, John Wiley \& Sons, 2009.

[4] F. Farzami, K. Forooraghi, and M. Norooziarab, "Miniaturization of a Microstrip Antenna Using a Compact and Thin Magneto-Dielectric Substrate", IEEE Antennas Wirel. Propag. Lett., Vol. 10, pp. 1540-1542, 2011.

[5] S. Kumar and D. K. Vishwakarma, "Miniaturisation of microstrip patch antenna using an artificial planar magneto-dielectric meta-substrate", IET Microwaves, Antennas Propag., Vol. 10, No. 11, pp. 1235-1241, 2016.

[6] P. Mookiah and K. R. Dandekar, "MetamaterialSubstrate Antenna Array for MIMO Communication System", IEEE Trans. Antennas Propag., Vol. 57, No. 10, pp. 3283-3292, 2009.

[7] M. Farahani, M. Akbari, M. Nedil, A. R. Sebak, and T. A. Denidni, "Miniaturised circularlypolarised antenna with high-constitutive parameter substrate", Electron. Lett., Vol. 53, No. 20, pp. 1343-1344, 2017.

[8] B. R. S. Reddy and D. Vakula, "Compact Zigzag-Shaped-Slit Microstrip Antenna With Circular Defected Ground Structure for Wireless Applications", IEEE Antennas Wirel. Propag. Lett., Vol. 14, pp. 678-681, 2015.

[9] J. Liu, W.-Y. Yin, and S. He, "A new defected ground structure and its application for miniaturized switchable antenna", Prog. Electromagn. Res., Vol. 107, pp. 115-128, 2010.

[10] A. A. Salih and M. S. Sharawi, "A Dual-Band Highly Miniaturized Patch Antenna," IEEE Antennas and Wireless Propagation Letters, Vol. 15. pp. 1783-1786, 2016.

[11] C. Ding, Y. J. Guo, P. Y. Qin, and Y. Yang, "A Compact Microstrip Phase Shifter Employing Reconfigurable Defected Microstrip Structure (RDMS) for Phased Array Antennas", IEEE Trans. Antennas Propag., Vol. 63, No. 5, pp. 1985-1996, 2015.

[12] M. T. Islam and M. S. Alam, "Compact EBG structure for alleviating mutual coupling between patch antenna array elements", Prog. Electromagn. Res., Vol. 137, pp. 425-439, 2013.

[13] S. Ghosh, T. N. Tran, and T. Le-Ngoc, "DualLayer EBG-Based Miniaturized Multi-Element Antenna for MIMO Systems," IEEE Trans. Antennas Propag., Vol. 62, No. 8, pp. 39853997, 2014.

[14] K. S. Sultan, H. H. Abdullah, E. A. Abdallah, and E. A. Hashish, "Low-SAR, Miniaturized Printed Antenna for Mobile, ISM, and WLAN Services," IEEE Antennas Wirel. Propag. Lett., Vol. 12, pp. 1106-1109, 2013.

[15] B. P. Smyth, S. Barth, and A. K. Iyer, "DualBand Microstrip Patch Antenna Using Integrated Uniplanar Metamaterial-Based EBGs," IEEE Trans. Antennas Propag., Vol. 64, No. 12, pp. 5046-5053, 2016.

[16] N. Jaglan, S. D. Gupta, E. Thakur, D. Kumar, B. K. Kanaujia, and S. Srivastava, "Triple band notched mushroom and uniplanar EBG structures based UWB MIMO/Diversity antenna with enhanced wide band isolation", AEU - Int. J. Electron. Commun., Vol. 90, pp. 36-44, 2018.

[17] H. H. Park, "Reduction of Electromagnetic Noise Coupling to Antennas in Metal-Framed Smartphones Using Ferrite Sheets and Multi-Via EBG Structures", IEEE Trans. Electromagn. Compat., Vol. 60, No. 2, pp. 394-401, 2018.

[18] S. Ebadi and A. Semnani, "Mutual coupling reduction in waveguide-slot-array antennas using electromagnetic bandgap (EBG) structures", 
IEEE Antennas Propag. Mag., Vol. 56, No. 3, pp. 68-79, 2014.

[19] S. Wang and Z. Du, "Decoupled Dual-Antenna System Using Crossed Neutralization Lines for LTE/WWAN Smartphone Applications", IEEE Antennas Wirel. Propag. Lett., Vol. 14, pp. 523526, 2015.

[20] Y. Wang and Z. Du, "A Wideband Printed DualAntenna With Three Neutralization Lines for Mobile Terminals", IEEE Trans. Antennas Propag., Vol. 62, No. 3, pp. 1495-1500, 2014.

[21] S. Zhang and G. F. Pedersen, "Mutual Coupling Reduction for UWB MIMO Antennas With a Wideband Neutralization Line", IEEE Antennas Wirel. Propag. Lett., Vol. 15, pp. 166-169, 2016.

[22] W. Qiao, X. Gao, X. Yu, S. M. Li, Y.-N. Jiang, and H.-F. Ma, "Ultra-Compact Microstrip Antenna Array and Miniaturized Feeding Network", Prog. Electromagn. Res., Vol. 71, pp. 111-122, 2017.

[23] D.-G. Fang, Antenna Theory and Microstrip Antennas. CRC Press, 2009.

[24] D. Guha and Y. M. M. Antar, Microstrip and printed antennas: new trends, techniques and applications, John Wiley \& Sons, 2011.

[25] R. Garg, I. Bahl, and M. Bozzi, Microstrip lines and slotlines, Artech house, 2013.

[26] M. A. Abdalla and A. A. Ibrahim, "Compact and Closely Spaced Metamaterial MIMO Antenna With High Isolation for Wireless Applications", IEEE Antennas Wirel. Propag. Lett., Vol. 12, pp. 1452-1455, 2013.

[27] Y. Chen and C. Chang, "Design of a fourelement multiple-input-multiple-output antenna for compact long-term evolution small-cell base stations", IET Microwaves, Antennas Propag., Vol. 10, No. 4, pp. 385-392, 2016.

[28] D. Sipal, M. P. Abegaonkar, and S. K. Koul, "Easily Extendable Compact Planar UWB MIMO Antenna Array", IEEE Antennas Wirel. Propag. Lett., Vol. 16, pp. 2328-2331, 2017.

[29] M. Li, Q. L. Li, B. Wang, C. F. Zhou, and S. W. Cheung, "Miniaturized Dual-Band Base Station Array-Antenna Using Band Notch Dipole Antenna Elements and AMC Reflectors", IEEE Trans. Antennas Propag., p. 1, 2018. 